\title{
Metal-Organic Frameworks and Their Derivatives for Photocatalytic Water Splitting
}

\author{
Fuzhan Song (D), Wei Li (D) and Yujie Sun * (D) \\ Department of Chemistry and Biochemistry, Utah State University, Logan, UT 84322, USA; \\ fuzhan.song@aggiemail.usu.edu (F.S.); wei.linano@aggiemail.usu.edu (W.L.) \\ * Correspondence: yujie.sun@usu.edu; Tel.: +1-435-797-7608 \\ Academic Editor: Matthias Bauer \\ Received: 19 April 2017; Accepted: 24 June 2017; Published: 28 June 2017
}

\begin{abstract}
Amongst many strategies for renewable energy conversion, light-driven water splitting to produce clean $\mathrm{H}_{2}$ represents a promising approach and has attracted increasing attention in recent years. Owing to the multi-electron/multi-proton transfer nature of water splitting, low-cost and competent catalysts are needed. Along the rapid development of metal-organic frameworks (MOFs) during the last two decades or so, MOFs have been recognized as an interesting group of catalysts or catalyst supports for photocatalytic water splitting. The modular synthesis, intrinsically high surface area, tunable porosity, and diverse metal nodes and organic struts of MOFs render them excellent catalyst candidates for photocatalytic water splitting. To date, the application of MOFs and their derivatives as photocatalysts for water splitting has become a burgeoning field. Herein, we showcase several representative MOF-based photocatalytic systems for both $\mathrm{H}_{2}$ and $\mathrm{O}_{2}$ evolution reactions (HER, OER). The design principle of each catalytic system is specifically discussed. The current challenges and opportunities of utilizing MOFs for photocatalytic water splitting are discussed in the end.
\end{abstract}

Keywords: metal-organic framework; photocatalysis; water splitting

\section{Introduction}

The ever-increasing global energy demand, depletion of fossil fuel reserves, together with the climate change resulting from fossil fuel consumption all motivate the exploration of alternative energy solutions, which are preferably based on renewable and environmentally friendly energy sources [1-6]. The transformation from fossil fuel-based economy to renewable energy-driven economy calls for the development of low-cost and competent catalysts for the capture and storage of intermittent renewable energy sources, like solar and wind. Among various green energy carrier candidates, dihydrogen $\left(\mathrm{H}_{2}\right)$ is particularly attractive, not only because of its high gravimetric energy density (120 $\mathrm{kJ} \cdot \mathrm{g}^{-1}$, by comparison the gravimetric energy density of petroleum is $44 \mathrm{~kJ} \cdot \mathrm{g}^{-1}$ ) [7-9], but also because of its clean nature (the sole product of $\mathrm{H}_{2}$ combustion is water). The current industrial approaches for $\mathrm{H}_{2}$ production, such as steam methane reforming and coal gasification, are very energy intensive and rely highly on fossil fuels [10-19]. Therefore, it remains a great necessity to develop alternative low-cost methods to produce $\mathrm{H}_{2}$, ideally driven by renewable energy sources. Within this context, photocatalytic water splitting emerged as a very appealing method in producing $\mathrm{H}_{2}$ from solar energy and water [20,21]. Since the pioneering work of Fujishima and Honda in 1972 that $\mathrm{TiO}_{2}$ was able to catalyze water splitting to produce $\mathrm{H}_{2}$ and $\mathrm{O}_{2}$ under ultraviolet light irradiation, the last four-and-a-half decades have witnessed a tremendous growth in developing various competent photocatalytic systems for light-driven water splitting [22-28]. A large number of light-absorbing materials (semiconductors) and complexes (photosensitizers), as well as photocatalysts have been 
developed, albeit the quantum yield of $\mathrm{H}_{2}$ production and solar energy conversion efficiency both require further improvement for large-scale applications.

During the last two decades, a new type of inorganic-organic hybrid and crystalline materials of high porosity, named metal-organic frameworks (MOFs), have attracted intense academic interest because of the following reasons [29-37]. MOFs are constructed by connecting metal and metal cluster nodes with organic bridging ligands in three-dimensional space. Therefore, a rich library of metal cations and organic ligands are available for the formation of diverse MOFs, enabling facile modulation of each component in MOFs. In addition, the intrinsically high surface area and regular pores and channels allow efficient interaction between substrates and reaction sites, beneficial to the overall catalytic performance. Table 1 summarizes the physical properties of representative MOFs discussed herein. Finally, MOFs are solid materials which might be able to be separated from reaction mixture for recycling utilization. Besides directly acting as photocatalysts for water splitting, carbonization of appropriate MOFs will result in metal/metal oxide nanoparticles embedded in highly porous carbon matrices resulting from the original organic ligands. In this case, the original MOFs not only provide the metal and carbon sources but also act as the sacrificial templates. The final hybrid composites can also be utilized for various photocatalytic applications including water splitting [38-40]. Owing to the aforementioned advantages, MOFs and their derivatives have been widely employed as photocatalysts for $\mathrm{H}_{2}$ production through water splitting [41]. In this short review, we do not intend to present a comprehensive overview of MOF-based photocatalytic systems for water splitting. Instead, we will introduce several representative MOF or MOF-derived photocatalysts and highlight their designing principle in order to achieve enhanced performance relative to their homogeneous/heterogeneous counterparts. It is our hope that this mini review will provide the audience with a flavor of the burgeoning field of photocatalytic water splitting utilizing MOFs and their derivatives.

\section{Photocatalytic $\mathrm{H}_{2}$ Evolution Utilizing MOF-based Photocatalysts}

Photocatalytic water splitting consists of two half-reactions: photocatalytic $\mathrm{H}_{2}$ and $\mathrm{O}_{2}$ evolution reactions (HER and OER). Each half-reaction involves the transfer of multiple protons and multiple electrons with slow kinetics under ambient conditions. Consequently, competent photocatalysts are desired for both HER and OER. In this section, we will first introduce the application of MOF-based photocatalytic systems for $\mathrm{H}_{2}$ production.

The first example of a MOF-based catalyst for photocatalytic $\mathrm{H}_{2}$ evolution was reported by Mori et al. in 2009 [42]. A Ru-MOF constructed with paddlewheel diruthenium cores $\left(\left[\mathrm{Ru}_{2}(p-\mathrm{BDC})_{2}\right]_{n}\right.$, $p$-BDC $=1$,4-benzenedicarboxylate) could act as active sites for water reduction to $\mathrm{H}_{2}$ in the presence of $\left[\mathrm{Ru}(\mathrm{bpy})_{3}\right]^{2+}$ (bpy = 2,2'-dipyridyl), $\mathrm{MV}^{2+}$ (methyl viologen, $N, N^{\prime}$-dimethyl-4,4'-bipyridinium dichloride), and EDTA-2Na (ethylenediaminetetraacetic acid disodium salt), each of which played the role of photosensitizer, electron relay, and sacrificial electron donor, respectively (Figure 1). Control experiments without photosensitizer or electron relay did not produce any $\mathrm{H}_{2}$ under visible light irradiation, which indicated that $\left[\mathrm{Ru}_{2}(p-\mathrm{BDC})_{2}\right]_{n}$ itself did not exhibit effective light absorption for photocatalysis. Compared with the molecular counterpart $\mathrm{Ru}_{2}\left(\mathrm{CH}_{3} \mathrm{COO}\right)_{4} \mathrm{BF}_{4},\left[\mathrm{Ru}_{2}(p-\mathrm{BDC})_{2}\right]_{n}$ was far more superior in photocatalyzing $\mathrm{H}_{2}$ production, resulting in a nearly 10 times higher turnover number (TON) during the first hour of visible light irradiation $(\lambda=420 \mathrm{~nm})$. It is believed that almost all of the catalytic reaction occurred on $\left[\mathrm{Ru}_{2}(p-\mathrm{BDC})_{2}\right]_{n}$ surface and in the inner pore space near to the surface, because the pore size of $\left[\mathrm{Ru}_{2}(p-\mathrm{BDC})_{2}\right]_{n}$ is small and does not allow $\mathrm{MV}^{2+}$ to enter the pores freely. However, the overall turnover number based on Ru-MOF (TON $=8.16$, Table 2 ) was mediocre and the quantum yield $(4.82 \%)$ required further improvement. In addition, expensive photosensitizer $\left[\mathrm{Ru}(\mathrm{bpy})_{3}\right]^{2+}$ was required for the production of $\mathrm{H}_{2}$. Following this work, Mori's group also reported a series of similar Ru-MOFs [43] and Rh-MOFs [44] as photocatalysts for $\mathrm{H}_{2}$ evolution from water under visible light irradiation. 


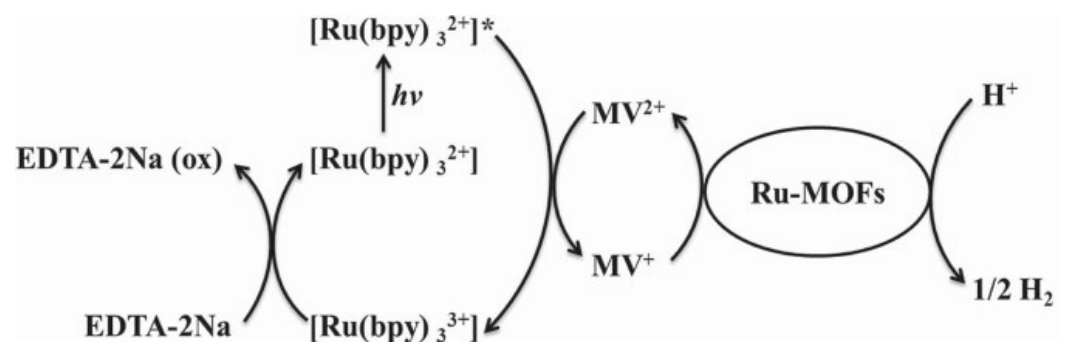

Figure 1. The reaction scheme of photochemical $\mathrm{H}_{2}$ production from water using $\mathrm{Ru}-\mathrm{MOF}$ in the presence of $\mathrm{Ru}(\mathrm{bpy})_{3}{ }^{2+}, \mathrm{MV}^{2+}$, and EDTA-2Na. Reproduced with permission from ref. [42], Royal Society of Chemistry.

Besides acting as the direct catalyst for photocatalytic $\mathrm{H}_{2}$ generation, MOFs can also be utilized as photosensitizers. For instance, Garcia and co-workers reported two highly water-stable Zr-based MOFs in 2010, UiO-66 $\left(\mathrm{Zr}_{6} \mathrm{O}_{4}(\mathrm{OH})_{4}(\mathrm{BDC})_{12}\right.$, where $\mathrm{BDC}=1$,4-benzenedicarboxylate) and UiO-66 $\left(\mathrm{NH}_{2}\right)$ $\left(\mathrm{Zr}_{6} \mathrm{O}_{4}(\mathrm{OH})_{4}(\mathrm{ATA})_{12}\right.$, where ATA $=2$-aminoterephthalate), which were able to show appreciable light absorption depending on organic ligand modification [45]. The two MOFs are isoreticular and they both contain hexameric $\mathrm{Zr}_{6} \mathrm{O}_{32}$ units as the metal clusters linked by 12 bridging ligands (BDC or ATA). The remarkable water stability of these two Zr-based MOFs enabled their application for photocatalysis applications, including water splitting. Even more exciting is that by tuning the bridging ligand, amending an amino group on the benzene ring of BDC, a significant bathochromic shift in the absorbance spectrum was obtained for UiO-66 $\left(\mathrm{NH}_{2}\right)$ as shown in Figure 2a. An intense absorption band between 300 and $400 \mathrm{~nm}$ with an absorption maximum at $360 \mathrm{~nm}$ was achieved for UiO-66 $\left(\mathrm{NH}_{2}\right)$. Such a ligand modification did not compromise the crystallinity and water stability of UiO-66 $\left(\mathrm{NH}_{2}\right)$ compared to the parent UiO-66. Even though these $\mathrm{Zr}$-based MOFs did not exhibit appreciable $\mathrm{H}_{2}$ production by themselves under visible light irradiation, decent amounts of $\mathrm{H}_{2}$ were generated when $\mathrm{Pt}$ nanoparticles were introduced as cocatalysts, which could accelerate charge separation and reduce the reaction barriers towards $\mathrm{H}_{2}$ formation. Figure $2 \mathrm{~b}$ compares the $\mathrm{H}_{2}$ evolution performance of four samples. It is apparent that the presence of $\mathrm{Pt}$ substantially increased the activity towards photocatalytic $\mathrm{H}_{2}$ production and $\mathrm{UiO}-66\left(\mathrm{NH}_{2}\right)$ was more active than UiO-66. Thanks to the modular synthesis of MOFs, this work vividly demonstrates how to take advantage of ligand modification to achieve enhanced photocatalytic activities of MOF-based catalysts.
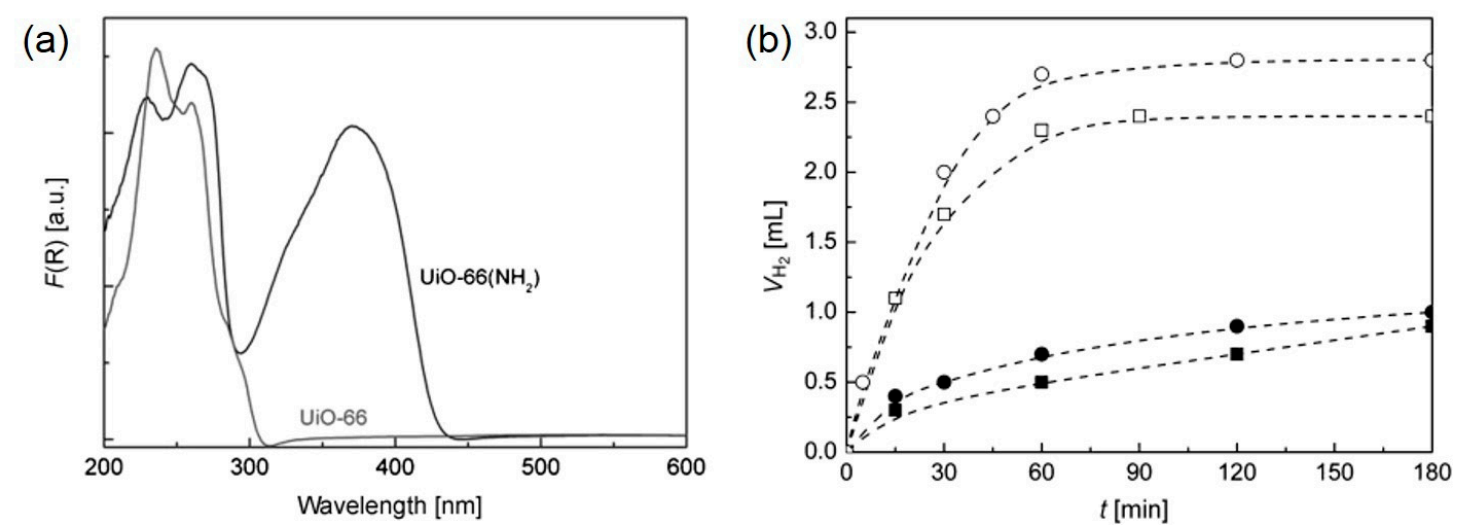

Figure 2. (a) UV-vis spectra of $\mathrm{UiO}-66$ and $\mathrm{UiO}-66\left(\mathrm{NH}_{2}\right) \mathrm{MOFs}$; (b) Volume of $\mathrm{H}_{2}$ evolved during the photocatalytic reactions using UiO-66 (solid square), UiO-66/Pt (hollow square), UiO-66 $\left(\mathrm{NH}_{2}\right)$ (solid dot) and UiO-66 $\left(\mathrm{NH}_{2}\right) / \mathrm{Pt}$ (hollow dot). Reproduced with permission from ref. [45], Wiley-VCH.

The aforementioned photocatalytic systems proceeded through the ligand-to-cluster charge transfer mechanism for $\mathrm{H}_{2}$ production. It was reasoned that an alternative titanium-oxo cluster would 
possess a more positive-lying conduction band than that of the zirconium counterpart. Therefore, more efficient charge transfer from the excited organic linkers to the metal clusters would be realized together with a higher yield of photocatalytic $\mathrm{H}_{2}$ production. Following this rationale, Matsuoka et al. prepared an amino-functionalized Ti (IV) MOF (Ti-MOF-NH $\mathrm{N}_{2}$ ) which utilized the same organic linker 2-amino-1,4-benzenedicarboxylic acid [46]. In contrast to its counterpart Ti-MOF with the conventional 1,4-benzenedicarboxylic acid linker (MIL-125), Ti-MOF-NH $\mathrm{NH}_{2}$ indeed exhibited intense absorption in the visible region with its absorption tail beyond $500 \mathrm{~nm}$ (Figure $3 \mathrm{a}$ ). When $\mathrm{Pt}$ nanoparticles were photodeposited into the MOF pores and triethanolamine (TEOA) was utilized as the sacrificial electron donor, light-to-cluster charge transfer took place for Ti-MOF-NH $\mathrm{Hnder}_{2}$ visible light irradiation. As schematically displayed in Figure 3b, photogenerated electrons were transferred from the excited BDC- $\mathrm{NH}_{2}$ group to the conduction band of the titanium-oxo cluster, followed by migration to $\mathrm{Pt}$ cocatalysts for eventual proton reduction to $\mathrm{H}_{2}$. Similar strategy has been adopted by the Yamashita group to synthesize an amine-functionalized MIL-101(Cr) photocatalyst for photocatalytic $\mathrm{H}_{2}$ production [47]. These works demonstrated that modifying the metal clusters while keeping the same organic ligands would also lead to various photocatalytic activities for water splitting, highlighting the beauty of the modular synthesis of MOFs for catalysis applications.
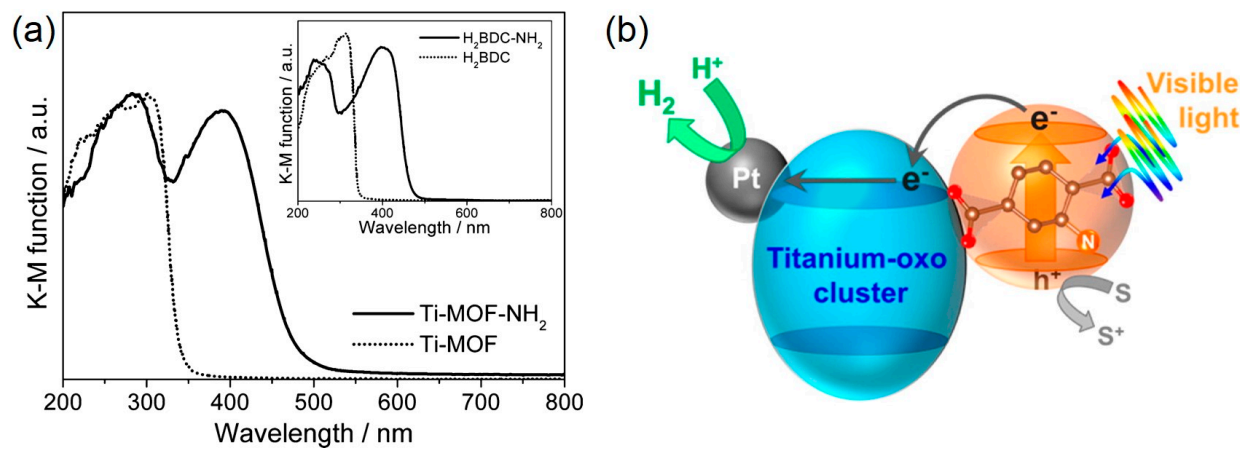

Figure 3. (a) Diffuse reflectance UV-vis (DRUV-vis) spectra of Ti-MOF (dotted line) and Ti-MOF-NH 2 (solid line). Inset shows the DRUV-vis spectra of $\mathrm{H}_{2} \mathrm{BDC}$ (dotted line) and $\mathrm{H}_{2} \mathrm{BDC}-\mathrm{NH}_{2}$ (solid line); (b) Schematic illustration of photocatalytic $\mathrm{H}_{2}$ production reaction over Pt-supported Ti-MOF- $\mathrm{NH}_{2}$. Reproduced with permission from ref. [46], American Chemical Society.

Another interesting and also widely studied organic species for visible light absorption is porphyrin and its derivatives. Following the same strategy described above, Rosseinsky and coworkers explored the photocatalytic $\mathrm{H}_{2}$ production performance of porphyrin-incorporated MOFs: $\mathrm{H}_{2} \mathrm{TCPP}[\mathrm{AlOH}]_{2}\left(\mathrm{DMF}_{3}\left(\mathrm{H}_{2} \mathrm{O}\right)_{2}\right.$ (Al-MOF, where $\mathrm{H}_{2} \mathrm{TCPP}=$ meso-tetra(4-carboxy-phenyl)porphyrin) and the zinc metalated $\mathrm{ZnTCPP}[\mathrm{AlOH}]_{2}(\mathrm{Al} / \mathrm{Zn}-\mathrm{MOF})$ [48]. Owing to the presence of porphyrin as the organic linker, the absorption spectrum of Al-MOF showed a strong Soret band at $415 \mathrm{~nm}$ and four $Q$ bands between 500 and $600 \mathrm{~nm}$ (Figure 4a). When a zinc cation was metalated into the porphyrin core of $\mathrm{Al}-\mathrm{MOF}$, the resulting $\mathrm{Al} / \mathrm{Zn}-\mathrm{MOF}$ presented a slightly red-shifted Soret band at $425 \mathrm{~nm}$ and only two $Q$ bands between 550 and $650 \mathrm{~nm}$ due to the higher symmetry of the metalated compound. Both Al-MOF and $\mathrm{Al} / \mathrm{Zn}-\mathrm{MOF}$ were employed as photosensitizers to produce $\mathrm{H}_{2}$ under visible light irradiation in the presence of colloidal platinum and sacrificial EDTA. The authors also attempted to employ $\mathrm{MV}^{2+}$ cations as electron acceptors/mediators to facilitate the reaction rate. Unfortunately, a rather low quantum yield (less than $0.01 \%$ ) of $\mathrm{H}_{2}$ production was obtained after $15 \mathrm{~h}$ photoirradiation. It was postulated that such a poor activity was mainly due to the limited diffusion of $\mathrm{MV}^{2+}$ within the MOF pores. Nevertheless, a second approach with no $\mathrm{MV}^{2+}$ but higher concentration of platinum was adopted to conduct the photocatalysis of $\mathrm{H}_{2}$ production catalyzed by both Al-MOF and $\mathrm{Al} / \mathrm{Zn}-\mathrm{MOF}$ (Figure 4b). Both MOFs showed decent photocatalytic performance in producing $\mathrm{H}_{2}$, reaching a rate of 100 and $200 \mu \mathrm{mol} \cdot \mathrm{g}^{-1} \cdot \mathrm{h}^{-1}$ for $\mathrm{Al} / \mathrm{Zn}-\mathrm{MOF}$ and Al-MOF, respectively. Control experiments of removing all the solid components for photocatalysis were also carried out to prove 
that indeed $\mathrm{H}_{2}$ was produced from the heterogeneous MOF-based photocatalytic systems rather than some unknown homogeneous species.
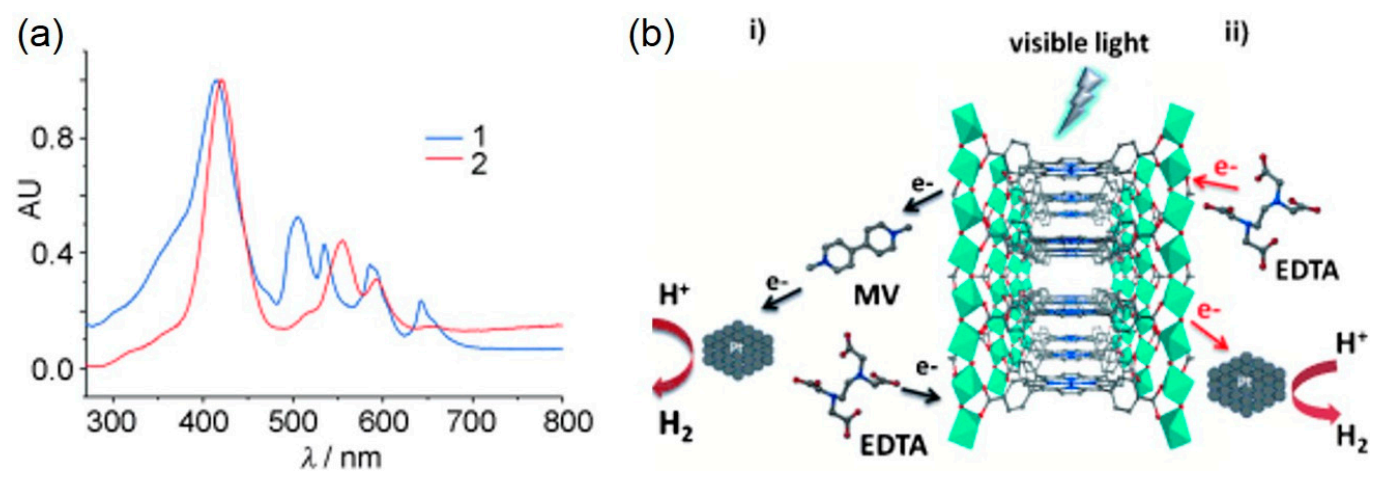

Figure 4. (a) UV/Vis solid-state absorption spectra of $\mathbf{1}$ and 2; (b) The photocatalytic reaction using $\mathrm{Al} / \mathrm{Zn}-\mathrm{MOF}$. (i) Reaction involving $\mathrm{Al} / \mathrm{Zn}-\mathrm{MOF}, \mathrm{MV}$, colloidal Pt, and EDTA. (ii) Reaction involving $\mathrm{Al} / \mathrm{Zn}-\mathrm{MOF}$, colloidal Pt, and EDTA. Reproduced with permission from ref. [48], Wiley-VCH.

In addition to simply mixing MOFs and Pt nanoparticles for photocatalysis, the tunable cavities of MOFs can be purposely designed to encapsulate platinum nanoparticles for intimate interaction between light-absorbing sites and $\mathrm{H}_{2}$-evolving sites. In 2012, Lin and co-workers reported the synthesis of UiO-type MOFs (1 and 2) with diethyl (2,2'-bipyridine)-5, $5^{\prime}$-dicarboxylate (1) and dimethyl (2,2'-bipyridine)-5, $5^{\prime}$-dibenzoate (2) bridging ligands which were able to coordinate $\operatorname{Ir}(\mathrm{ppy})_{2}$ (ppy $=2$-phenylpyridine) units as phosphors for light absorption [49]. In situ photoreduction of $\mathrm{K}_{2} \mathrm{PtCl}_{4}$ resulted in the incorporation of Pt nanoparticles into the cavities of MOF 1 and 2. Figure $5 \mathrm{a}$ presents the schematic diagram for light-induced $\mathrm{H}_{2}$ evolution: excited iridium chromophores are reductively quenched by the sacrificial electron donor triethylamine (TEA) and subsequently promotes electron transfer to the encapsulated $\mathrm{Pt}$ nanoparticles where proton reduction to $\mathrm{H}_{2}$ takes place. Under visible light irradiation (> $420 \mathrm{~nm}$ ), it was found that Pt@2 showed the highest $\mathrm{H}_{2}$ evolution activity, achieving a TON of 7000 based on Ir content after a $48 \mathrm{~h}$ photolysis (shown in Table 2). Such a high activity was nearly five times that of its homogeneous control sample (Figure 5b). This work demonstrates that in addition to organic ligands as light-absorbing units, highly photoactive inorganic complexes can be incorporated into the linkers of MOFs for photocatalytic $\mathrm{H}_{2}$ production, further highlighting the design flexibility of MOFs for photocatalytic applications. Following this work, UiO-66/CdS/1\% reduced graphene oxide (RGO) [50] and RhB-sensitized Pt@UiO-66 [51] were also prepared and these MOF-based photocatalytic systems both showed enhanced catalytic performance for $\mathrm{H}_{2}$ generation compared to their homogeneous counterparts.
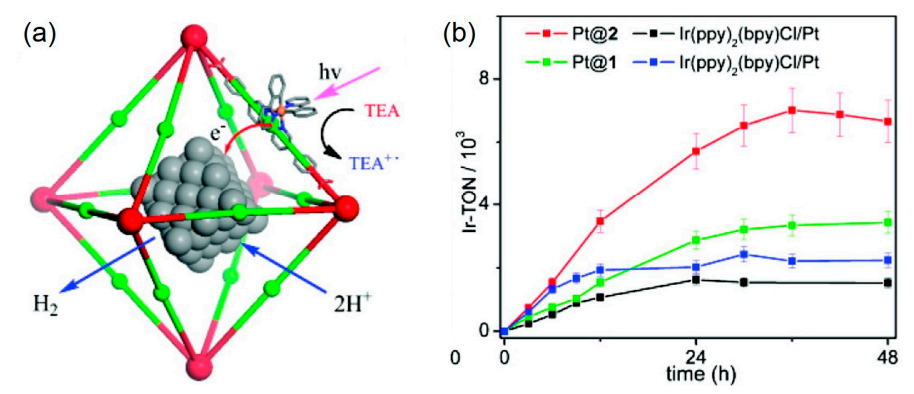

Figure 5. (a) A schematic diagram depicts the steps of photoinjection of electrons from MOF frameworks under light irradiation into Pt nanoparticles for the photocatalytic $\mathrm{H}_{2}$ evolution. Red: $\mathrm{Zr}_{6}(\mathrm{O})_{4}(\mathrm{OH})_{4}$ (carboxylate) ${ }_{12}$ cores; green: Ir-phosphor ligand; (b) Time-dependent $\mathrm{H}_{2}$ evolution curves of Pt@1 (green), Pt@2 (red), and homogeneous control [ $\left.\operatorname{Ir}(\mathrm{ppy})_{2}(\mathrm{bpy})\right] \mathrm{Cl} / \mathrm{K}_{2} \mathrm{PtCl}_{4}$ (blue: Pt/Ir: 86.0; black: Pt/Ir 24.2). Reproduced with permission from ref. [49], American Chemical Society. 
Besides Pt nanoparticles, Pt coordination complexes can also be utilized as $\mathrm{H}_{2}$ evolution catalysts. Recently, $\mathrm{Xu}$ and co-workers developed a new MOF material (MOF-253-Pt) by immobilizing $\mathrm{Pt}^{2+}$ into MOF-253 with 2,2-bipyridine-based linkers following a post-synthesis modification strategy (Figure 6a) [52]. The resultant MOF-253-Pt served both as a photosensitizer and a photocatalyst for $\mathrm{H}_{2}$ evolution under visible light irradiation. After the introduction of $\mathrm{Pt}$, an obvious red-shift in its absorption was observed (Figure 6b). The low-energy absorption in Pt-MOF-253 was due to the metal-to-ligand ( $\mathrm{Pt}^{\mathrm{II}} /$ bipyridine) charge transfer transition. The photocatalytic $\mathrm{H}_{2}$ generation rate was highly dependent on $\mathrm{pH}$ values. The optimum $\mathrm{pH}$ was found to be 8.5. At lower $\mathrm{pH}$ values, the protonated TEOA was a weak electron donor, while at higher $\mathrm{pH}$ values, TEOA was not able to form the hydride-diplatinum (II, III) species (a postulated reaction intermediate) and hence the driving force for $\mathrm{H}_{2}$ formation was diminished. Compared to the bare MOF-253 and the molecular $\mathrm{Pt}(\mathrm{bpydc}) \mathrm{Cl}_{2}$ (bpydc $=2,2^{\prime}$-bipyridine-5,5'-dicar-boxylic acid) complex, the hybrid Pt-MOF-253 photocatalytic system exhibited significantly improved photocatalytic activity for $\mathrm{H}_{2}$ evolution under visible light irradiation. The enhanced activity of Pt-MOF-253 was due to the short spacing between Pt...Pt, which was beneficial to the formation of the critical intermediate hydride-diplatinum (II, III), more efficient electron transfer within the MOF structure, and the slowed decomposition of the anchored $\mathrm{Pt}(\mathrm{bpy}) \mathrm{Cl}_{2}$ units in Pt-MOF-253. The overall photocatalytic cycle was schematically pictured in Figure 6c.
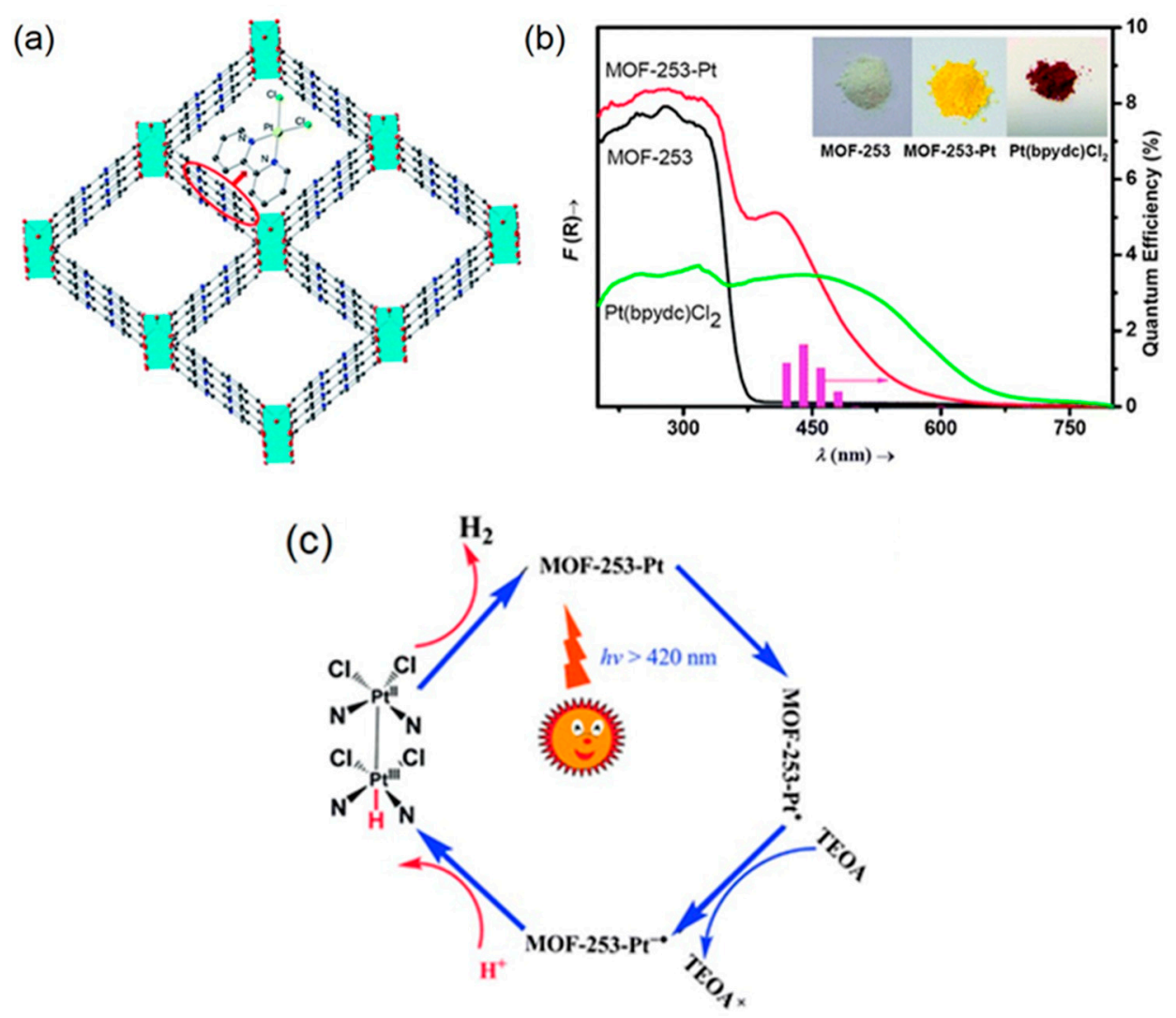

Figure 6. (a) Model structure of MOF-253-Pt, through post-synthetic modification of MOF-253 with $\mathrm{PtCl}_{2}$; (b) UV-vis absorption spectra of MOF-253, Pt-MOF-253, and $\mathrm{Pt}(\mathrm{bpydc}) \mathrm{Cl}_{2}$ together with $\mathrm{H}_{2}$ evolution quantum efficiencies of Pt-MOF-253 at different wavelengths. The color of three samples are shown in the inset; (c) A proposed mechanistic diagram of $\mathrm{H}_{2}$ evolution photocatalyzed by Pt-MOF-253. Reproduced with permission from ref. [52], Royal Society of Chemistry.

In order to develop cost-effective catalysts for future water splitting on an industrial scale, it is imperative to explore noble metal-free catalysts for $\mathrm{H}_{2}$ production from water. Such a trend has been well manifested in the electrocatalysis field which has witnessed the emergence of 1st-row 
transition metal-based complexes [53] and solid-state materials [54-59] as competent electrocatalysts for water splitting. One of those well-established molecular electrocatalysts for $\mathrm{H}_{2}$ evolution is cobaloxime complex. Recently, Gascon and co-workers introduced cobaloxime into the pores of $\mathrm{NH}_{2}$-MIL-125(Ti) following a "ship-in-the-bottle" strategy [60]. As shown in Figure 7a, the size selection of the pores in $\mathrm{NH}_{2}$-MIL-125(Ti) was crucial to the successful formation of the cobaloxime complex inside the MOF cavities. For instance, the intact cobaloxime complex was too large to diffuse into and out from the $\mathrm{NH}_{2}-\mathrm{MIL}-125$ (Ti) pore windows. However, the free ligand $(\mathrm{DOH})_{2} \mathrm{pn}$ $\left(N^{2}, N^{2 \prime}\right.$-propanediylbis(2,3-butanedione 2-imine 3-oxime)) was able to migrate into the internal channels of $\mathrm{NH}_{2}-\mathrm{MIL}-125$ (Ti). Upon the addition of $\mathrm{CoBr}_{2}$ as the cobalt source under aerobic conditions, cobaloxime was assembled inside the MOF pores. Such a strategy would minimize the exclusion of the $\mathrm{H}_{2}$ catalyst from the MOF cavities. Varying the initial amounts of the free ligand and $\mathrm{CoBr}_{2}$ could facilely tune the catalyst loading within the MOF structure. The pristine $\mathrm{NH}_{2}-\mathrm{MIL}-125(\mathrm{Ti})$ possessed a pore volume of $0.58 \mathrm{~cm}^{3} \cdot \mathrm{g}^{-1}$. After the loading of cobaloxime, the resulting Co@MOF exhibited an expected smaller pore volume of $0.46 \mathrm{~cm}^{3} \cdot \mathrm{g}^{-1}$. Figure $7 \mathrm{~b}$ presented the evolved $\mathrm{H}_{2}$ amount over $25 \mathrm{~h}$ photolysis under visible light irradiation $(\lambda>408 \mathrm{~nm})$. The cobaloxime-encapsulated Co@MOF clearly displayed a markedly improved photocatalytic performance for $\mathrm{H}_{2}$ evolution with nearly 20-fold higher $\mathrm{H}_{2}$ production rate compared to the pristine MOF. More importantly, Co@MOF possessed a high stability with a turnover frequency of $0.8 \mathrm{~h}^{-1}$ even after operating for $65 \mathrm{~h}$. Furthermore, the system could be recycled several times without any loss of activity (Figure 7c). Even though remarkable photocatalytic $\mathrm{H}_{2}$ evolution performance was achieved by this hybrid Co@MOF systems solely consisting of earth-abundant elements, the exact structure of the cobalt catalyst within the MOF pores remained unknown. However, it still strongly demonstrates that the modular design and synthesis of multicomponent MOF systems opens a new window to develop low-cost photocatalytic composites for $\mathrm{H}_{2}$ production from water.
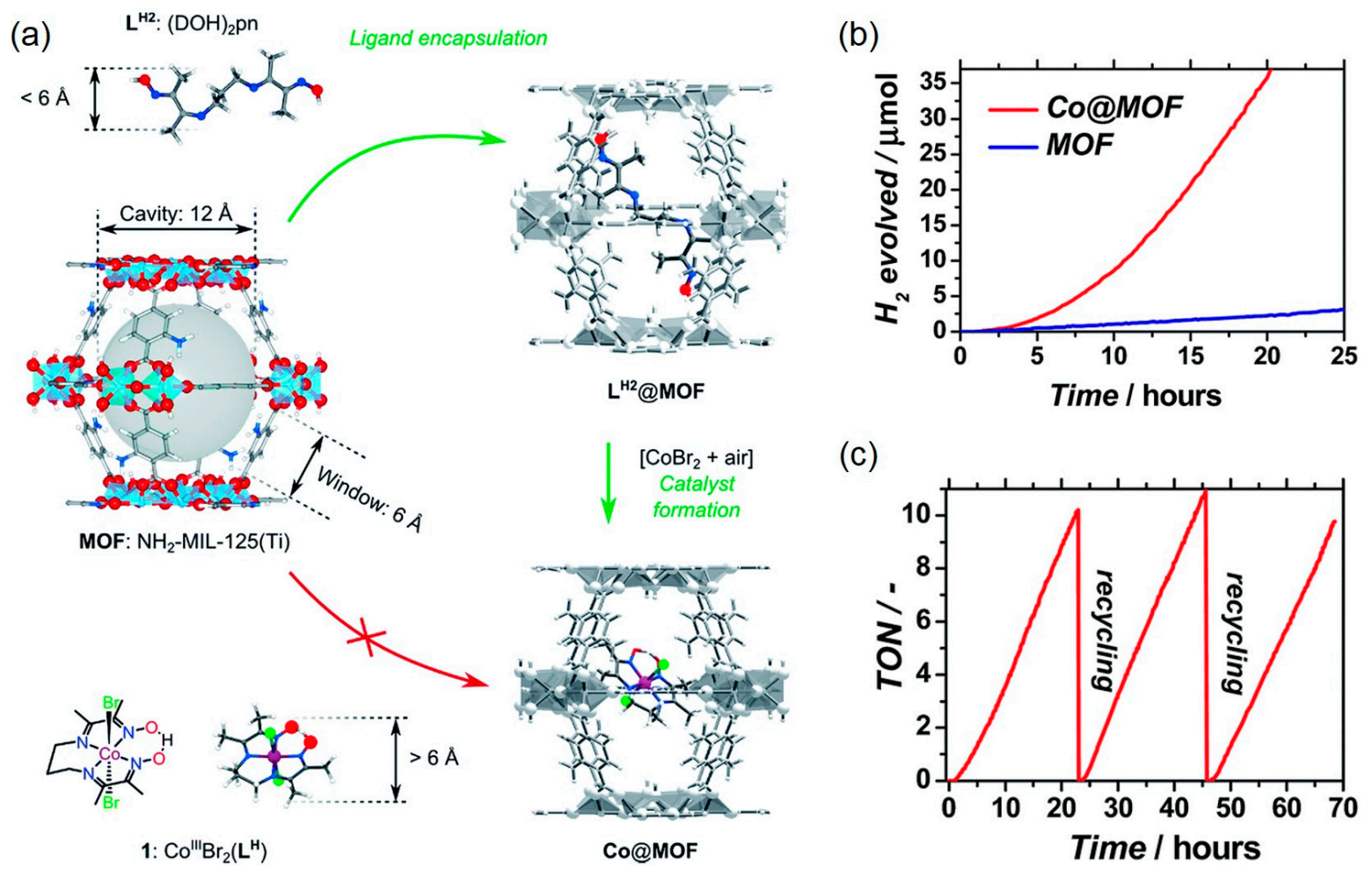

Figure 7. (a) "Ship-in-a-bottle" synthetic strategy for the preparation of Co@MOF; (b) Photocatalytic proton reduction using MOF and Co@MOF; (c) Recycling tests on Co@MOF bearing medium cobalt loading. Reproduced with permission from ref. [60], Royal Society of Chemistry. 


\section{3. $\mathrm{O}_{2}$ Evolution Catalyzed by MOF-based Hybrid Systems}

In contrast to the large number of MOF-based photocatalytic systems for $\mathrm{H}_{2}$ evolution, much fewer studies have been reported for the other half-reaction of water splitting, the $\mathrm{O}_{2}$ evolution reaction, utilizing MOF-based catalysts. This might be attributed to the harsh oxidizing condition of $\mathrm{O}_{2}$ evolution where most MOFs could not survive [61-63]. Nevertheless, a few MOF systems have still been reported with promising $\mathrm{O}_{2}$ evolution performance. The first work of MOF-based catalysts for water oxidation was reported by Lin et al. in 2011 [64]. Highly robust and porous $\mathrm{Zr}_{6} \mathrm{O}_{4}(\mathrm{OH})_{4}(\mathrm{bpdc})_{6}(\mathrm{UiO}-67, \mathrm{bpdc}=$ para-biphenyldicarboxylic acid $)$ framework was employed as a heterogeneous support to incorporate a variety of iridium and other complexes for various applications, including water oxidation. Following a mix-and-match synthetic strategies, three iridium complexes, [C $\left.{ }^{*}{ }^{*}{ }^{I I I}(\mathrm{dcppy}) \mathrm{Cl}\right]$ (MOF-1; $\quad \mathrm{Cp}^{*}=$ pentamethylcyclopentadienyl, $\mathrm{dcppy}=2$-phenylpyridine-5, $4^{\prime}$-dicarboxylic acid), $\quad\left[\mathrm{Cp}^{*} \mathrm{Ir}{ }^{\mathrm{III}}(\mathrm{dcbpy}) \mathrm{Cl}\right] \mathrm{Cl}$ (MOF-2; dcbpy = 2,2'-bipyridine-5,5'-dicarboxylic acid), and $\left[\operatorname{Ir}^{\mathrm{III}}(\mathrm{dcppy})_{2}\left(\mathrm{H}_{2} \mathrm{O}\right)_{2}\right] \mathrm{OTf}$ (MOF-3), were bound into UiO-67. The synthetic route and the corresponding molecular structures of the three iridium units are included in Figure 8. The water oxidation performance of MOF 1-3 was examined with $\mathrm{Ce}^{4+}$ as the chemical oxidant (Figure 9a). All the Ir-incorporated MOFs were effective water oxidation catalysts with TON values as high as 4.8 (Table 2) (MOF 1). Repeated catalytic cycles demonstrated robust stability of these MOFs for elongated water oxidation (Figure 9b). Control experiments confirmed that the observed water oxidation activities were originated from the heterogeneous MOFs. However, compared to their homogeneous counterparts, MOF 1-3 exhibited lower turnover frequencies (only $6.4-12.9 \%$ of the homogeneous catalyst activities). Such a decreased performance was rationalized by the fact that only those iridium complexes exposed on the MOF surfaces were involved in water oxidation, since the cerium nitrate anions were too bulky to enter the MOF channels. Therefore, in order to increase catalytic activity, Lin and co-workers further prepared two other $\mathrm{Zr}$-based MOFs with larger channels using two elongated dicarboxylate ligands [65]. These new MOFs showed enhanced water oxidation activity when using cerium nitrate as the oxidant. Although their instability and partial decomposition of the iridium complexes were observed under the water oxidation condition, these works presented the possibility of incorporating molecular active sites in MOFs structures for water oxidation, complementary to those homogeneous $\mathrm{O}_{2}$ evolution studies.

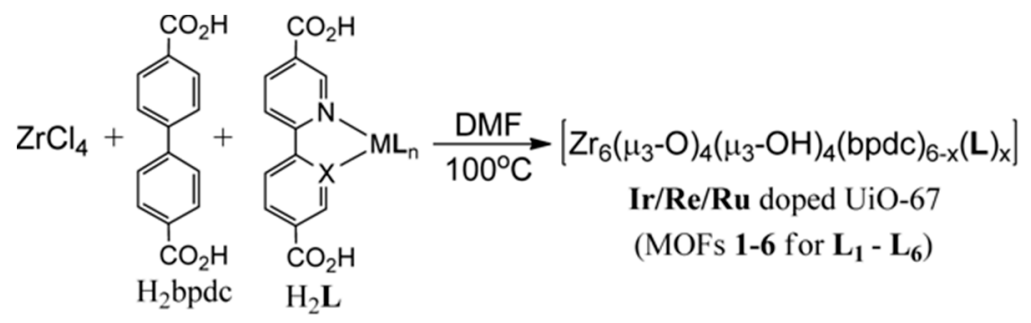

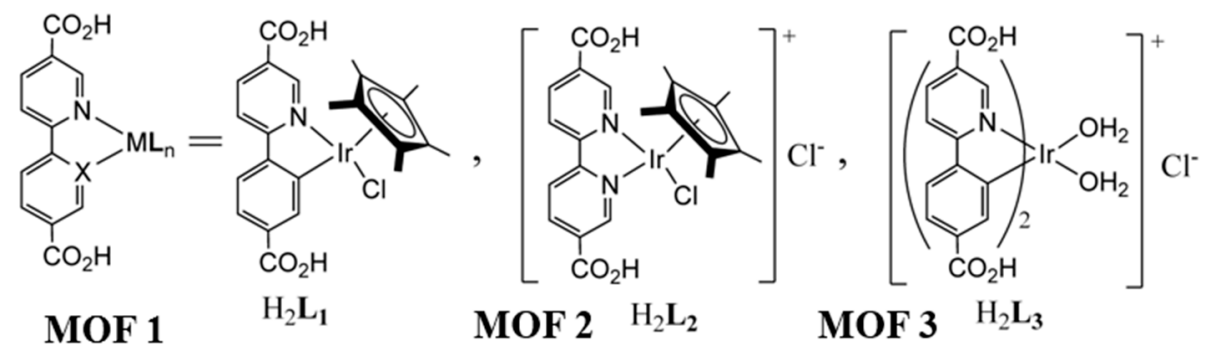

Figure 8. Synthesis of $\mathrm{Zr} / \mathrm{Ir}$ MOFs incorporating varying iridium catalysts for water oxidation. Reproduced with permission from ref. [64], American Chemical Society. 

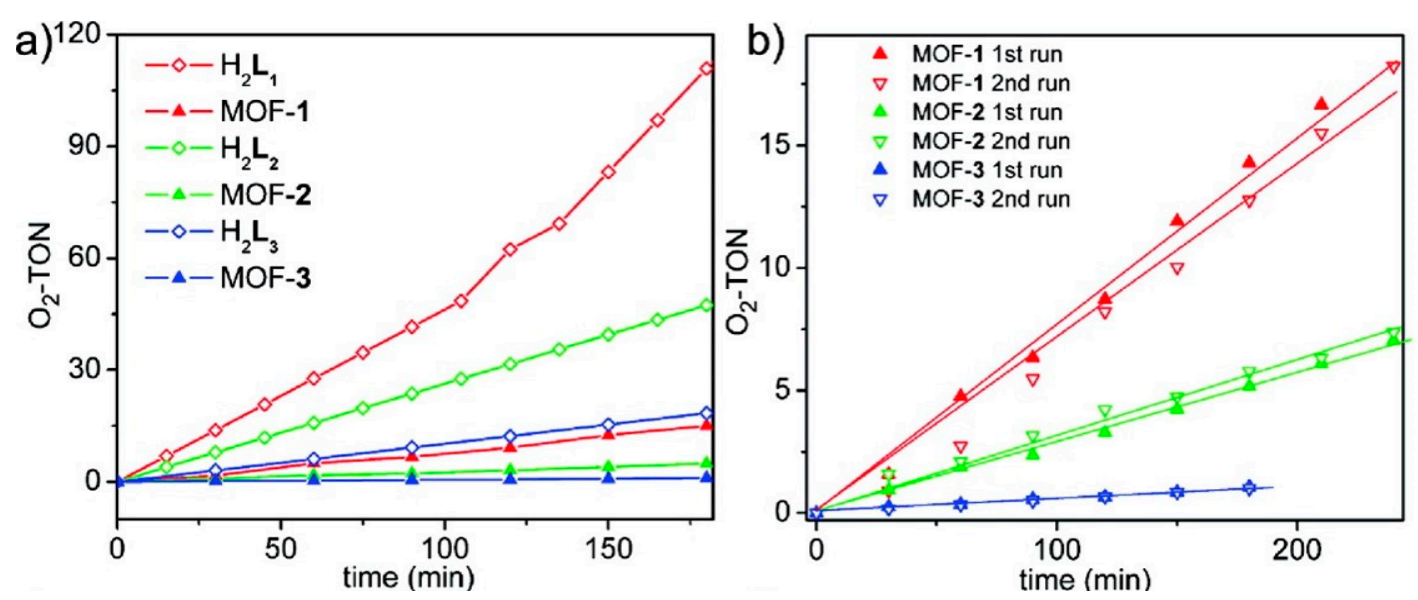

Figure 9. (a) Plots of $\mathrm{O}_{2}$ evolving turnover number $\left(\mathrm{O}_{2}-\mathrm{TON}\right)$ vs. time for MOFs $1-3$ and the homogeneous complexes; (b) Plots of $\mathrm{O}_{2}-\mathrm{TON}$ vs. time for reuse experiments of MOFs 1-3. Reproduced with permission from ref. [64], American Chemical Society.

\section{Photocatalytic Water Splitting Utilizing MOF-derived Photocatalysts}

Metal-organic frameworks not only represent attractive scaffolds for the incorporation of diverse components (phosphors, active sites, etc.) for photocatalytic water splitting, but also can act as sacrificial templates to produce a variety of highly porous carbon materials. Under certain conditions, multiple beneficial components for photocatalysis, including nonmetals, metals, and metal oxides, are embedded in those MOF-derived carbon composites. In fact, MOF-derived hybrid materials have been successfully employed in many fields, ranging from catalysis [66-71], supercapacitors [72], to batteries [73-75]. For photocatalytic water splitting, several representative MOF-derived systems are introduced herein. Following the MIL-101 structure, Lin and co-workers utilized microwave treatment to synthesize a MOF material with the formula of $\mathrm{Fe}_{3} \mathrm{OCl}\left(\mathrm{H}_{2} \mathrm{O}\right)(\mathrm{BDC})_{3}(\mathrm{BDC}=$ benzene dicarboxylate) [76]. Subsequently, the Fe-based MIL-101 particles were coated with an amorphous layer of $\mathrm{TiO}_{2}$ by acid-catalyzed hydrolysis and TALH (titanium (IV) bis(ammonium lactate)dihydroxide) condensation in water. The obtained core-shell particles were then calcined at $550{ }^{\circ} \mathrm{C}$ in air to form iron oxide covered with a shell of $\mathrm{TiO}_{2}\left(\mathrm{Fe}_{2} \mathrm{O}_{3} @ \mathrm{TiO}_{2}\right)$. Pt particles were deposited on the surface of $\mathrm{Fe}_{2} \mathrm{O}_{3} @ \mathrm{TiO}_{2}$ for photocatalytic $\mathrm{H}_{2}$ evolution. The overall synthetic scheme is outlined in Figure 10a. Compared to $\mathrm{Fe}_{2} \mathrm{O}_{3}, \mathrm{TiO}_{2}$, or their mixtures, the MOF-derived $\mathrm{Fe}_{2} \mathrm{O}_{3} @ \mathrm{TiO}_{2}$ showed superior photocatalytic performance for $\mathrm{H}_{2}$ generation under visible light irradiation $(\lambda>420 \mathrm{~nm})$ with triethylamine (TEA) as the sacrificial electron donor (Figure 10b). The amount of $\mathrm{H}_{2}$ produced increased linearly during the $48 \mathrm{~h}$ photolysis (Figure 10b inset). The MOF-derived photocatalyst also possessed high stability with nearly no decrease in activity for three photolysis cycles. Analogous strategies were adopted to prepare other MOF-derived hollow $\mathrm{Fe}_{2} \mathrm{O}_{3}-\mathrm{TiO}_{2}-\mathrm{PtO}_{x}$ systems employing MIL-88B as a sacrificial MOF template [77]. Promising photocatalytic $\mathrm{H}_{2}$ evolution rate was obtained from the $\mathrm{Fe}_{2} \mathrm{O}_{3}-\mathrm{TiO}_{2}-\mathrm{PtO}_{x}$ system as well.

Photocatalytic $\mathrm{H}_{2}$ evolution could also be realized by MOF-derived hybrid composites without noble-metal cocatalysts. For instance, Qiu et al. reported a magnetic photocatalyst derived from an iron MOF [78]. The magnetic nature of this photocatalyst enabled its easy separation from the reaction media for repeated use. In 2015, a cobalt-based MOF was utilized as a sacrificial template to prepare $\mathrm{Co}_{3} \mathrm{O}_{4} / \mathrm{TiO}_{2}$ for photocatalytic $\mathrm{H}_{2}$ production from water [79]. After calcination, $\mathrm{Co}_{3} \mathrm{O}_{4}$ and $\mathrm{TiO}_{2}$ were well dispersed throughout the composite. It was found that the close heterojunction between $\mathrm{Co}_{3} \mathrm{O}_{4}$ and $\mathrm{TiO}_{2}$ and the co-catalytic role of $\mathrm{C}_{\mathrm{O}_{3}} \mathrm{O}_{4}$ both resulted in fast interfacial charge transfer and efficient electron-hole separation, contributing to the overall photocatalytic performance. Very recently, a new mesoporous $\mathrm{p}-\mathrm{n}$ heterojunction semiconductor nanocomposite, $\mathrm{Cu}_{2} \mathrm{O} @ \mathrm{C}_{3} \mathrm{~N}$, was prepared 
by pyrolysis of a copper-based $\mathrm{MOF}, \mathrm{Cu}_{3}(\mathrm{BTC})_{2}$ (BTC $=1,3,5$-benzenetricarboylate) together with urea [80]. The obtained $\mathrm{Cu}_{2} \mathrm{O}_{3} \mathrm{C}_{3} \mathrm{~N}$ nanocomposite exhibited a lower band gap energy in comparison with bulk carbon nitride and $\mathrm{Cu}_{2} \mathrm{O}$, as well as dramatically enhanced photocatalytic activity for $\mathrm{H}_{2}$ production from water.

(a)

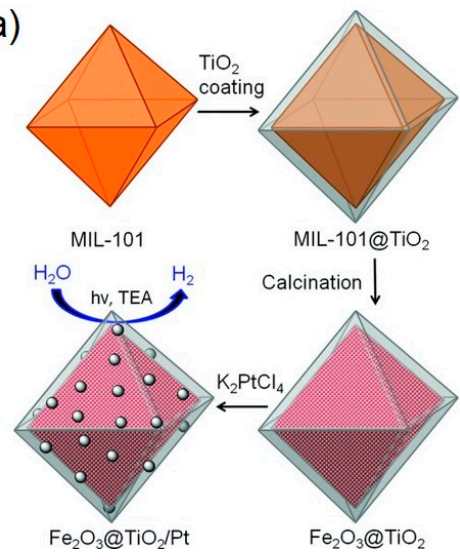

(b)

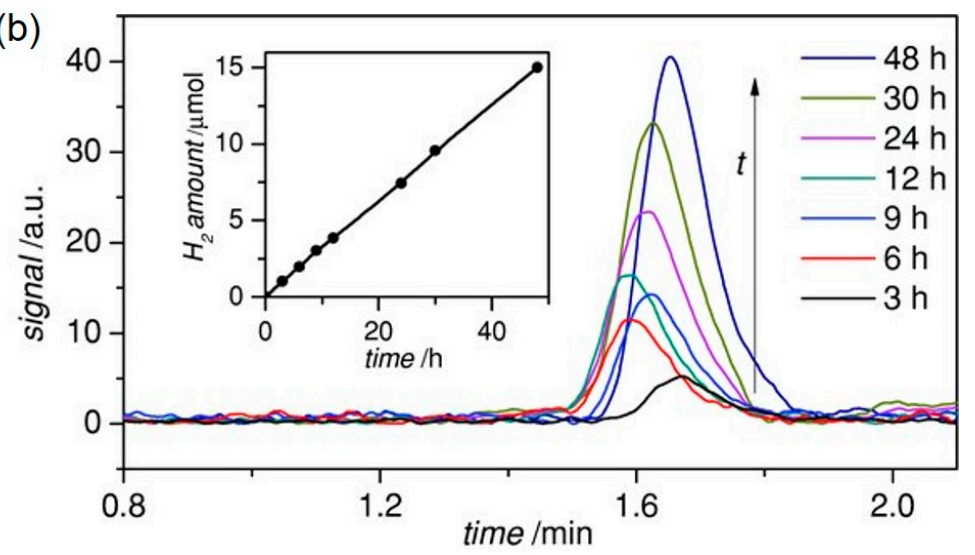

Figure 10. (a) MOF-templated synthesis of $\mathrm{Fe}_{2} \mathrm{O}_{3} @ \mathrm{TiO}_{2}$ by coating MIL-101 with $\mathrm{TiO}_{2}$ followed by calcination, and its use for photocatalytic $\mathrm{H}_{2}$ production after functionalized with Pt particles; (b) $\mathrm{H}_{2}$ produced by $\mathrm{Fe}_{2} \mathrm{O}_{3} @ \mathrm{TiO}_{2}$ in $20 / 1 v / v \mathrm{H}_{2} \mathrm{O} / \mathrm{TEA}$ at various time points over $48 \mathrm{~h}$, with a $420 \mathrm{~nm}$ filter. The inset shows the amount of $\mathrm{H}_{2}$ produced over this time period. Reproduced with permission from ref. [76], Wiley-VCH.

Table 1. The porosity properties of the representative metal-organic frameworks (MOFs).

\begin{tabular}{|c|c|c|c|c|}
\hline MOF & Surface Area $\left(\mathrm{m}^{2} \cdot \mathrm{g}^{-1}\right)$ & Pore Volume $\left(\mathrm{cm}^{3} \cdot \mathrm{g}^{-1}\right)$ & Space Groups & Reference \\
\hline Ru-MOF & 516.5 & 0.26 & P213 & [42] \\
\hline Ti-MOF & 1202 & & $\mathrm{I} / \mathrm{mmm}$ & [46] \\
\hline Ti-MOF-NH 2 & 1101 & & $14 / \mathrm{mmm}$ & [46] \\
\hline MIL-101-NH & 1436 & 0.98 & $F d-3 m: 2$ & [47] \\
\hline $\mathrm{Al}-\mathrm{MOF}$ & 1400 & 0.62 & $\mathrm{Cmmm}$ & [48] \\
\hline $\mathrm{Al} / \mathrm{Zn}-\mathrm{MOF}$ & 1200 & & $\mathrm{Cmm} 2$ & [48] \\
\hline Zr-MOF & 1194 & & $F 23$ & [49] \\
\hline $\mathrm{UiO}-66$ & 972 & & $F m-3 m$ & [50] \\
\hline Co@NH2MIL-125 & & 0.46 & $\mathrm{I} / \mathrm{mmm}$ & [60] \\
\hline Doped-UiO-67 (1) & 1254 & & & [64] \\
\hline Doped-UiO-67 (2) & 1947 & & & [64] \\
\hline Doped-UiO-67 (3) & 1410 & & & [64] \\
\hline Co-MOF & 520 & & $C 2 / c$ & [79] \\
\hline $\mathrm{Cu}-\mathrm{MOF}$ & 1182 & & $F m 3 m$ & [80] \\
\hline
\end{tabular}

Table 2. Comparison of photocatalytic properties of various photocatalysts.

\begin{tabular}{ccccc}
\hline Catalyst & TON & Time (h) & Photocatalytic Reactions & Ref. \\
\hline Ru-MOF & 8.16 & 4 & HER & {$[42]$} \\
Pt/NH 2 -MIL-101 & 110 & 6 & HER & {$[47]$} \\
Pt/Zr-MOF & 7000 & 48 & HER & {$[49]$} \\
Doped-UiO-67 (1) & 15 & 3 & OER & {$[64]$} \\
Doped-UiO-67 (2) & 6 & 3 & OER & {$[64]$} \\
Doped-UiO-67 (3) & 2 & 3 & OER & {$[64]$} \\
Zr/Ir MOF & 4 & 1 & OER & {$[65]$} \\
\hline
\end{tabular}

\section{Conclusions}

The last decade has witnessed the rapid advance in photocatalytic water splitting utilizing MOF-based and/or derived catalytic systems. This brief review has presented quite a few number of 
representative examples in this field. It is apparent that by taking advantage of the modular synthesis and rich diversity in the selection of inorganic and organic components, MOFs and their derivatives will certainly attract even more attention in the foreseeable future for catalytic applications, including water splitting. Even though a great progress has been achieved in producing $\mathrm{H}_{2}$ under visible light irradiation catalyzed by MOF-based composites, several challenges remain to be addressed. First of all, very few systems have been reported for photocatalytic $\mathrm{O}_{2}$ evolution from water. Since $\mathrm{H}_{2}$ production is only one of the two half-reactions of water splitting, it is equally if not more important to develop competent water oxidation catalysts, in order to realize water splitting for practical applications. More efforts need to be devoted to exploring the rich chemistry of MOFs and their derivatives in preparing highly robust and active photocatalytic systems for water oxidation under visible light irradiation. Secondly, most of those reported MOF-based photocatalysts require noble metal co-catalysts for the efficient production of $\mathrm{H}_{2}$, which is not economically attractive for industrial application. Economically competitive systems solely consisting of earth-abundant elements are highly desirable. In addition, complex and expensive organic linkers for some MOFs also seem to be problematic. A mixed-linker strategy with low-cost organic linkers might be a promising alternative to reduce the cost of desirable MOFs, which should deserve more attention in the future. More efforts should be shifted towards exploring mixed-organic linkers and 1st-row transition metal-based catalysts derived from MOFs for photocatalytic water splitting. Finally, the intrinsic activity and density of active sites of the photocatalysts should be further improved to meet the requirements of practical application. TONs ought to be $>1000$ for small-scale and high-value products, but it is better to be $>50,000$ for industrial applications. Currently, the reported activities (TON < 7000) of most MOF-based photocatalytic systems are still below the expectation for industrial application. Therefore, the unique features of MOFs, including large surface area, tunable pore volume and size, rich coordination chemistry, high crystallinity, and diverse three-dimensional structure, should be wisely utilized to maximize the overall catalytic performance. Molecular approaches of catalyst design coupled with materials science strategies in the development of MOF-based catalysts will undoubtedly lead to a very bright future for photocatalytic water splitting.

Acknowledgments: The authors would like to acknowledge the financial support of Utah State University. Yujie Sun also thanks National Science Foundation (CHE-1653978) and the Ralph E. Powe Junior Faculty Enhancement Award from Oak Ridge Associated Universities (ORAU).

Conflicts of Interest: The authors declare no conflict of interest.

\section{References}

1. Dresselhaus, M.S.; Thomas, I.L. Alternative energy technologies. Nature 2001, 414, 332-337. [CrossRef] [PubMed]

2. Turner, J.A. Sustainable hydrogen production. Science 2004, 305, 972-974. [CrossRef] [PubMed]

3. Lewis, N.S.; Nocera, D.G. Powering the planet: Chemical challenges in solar energy utilization. Proc. Natl. Acad. Sci. USA 2006, 103, 15729-15735. [CrossRef] [PubMed]

4. Cook, T.R.; Dogutan, D.K.; Reece, S.Y.; Surendranath, Y.; Teets, T.S.; Nocera, D.G. Solar Energy supply and storage for the legacy and nonlegacy worlds. Chem. Rev. 2010, 110, 6474-6502. [CrossRef] [PubMed]

5. Chu, S.; Majumdar, A. Opportunities and challenges for a sustainable energy future. Nature 2012, 488, 294-303. [CrossRef] [PubMed]

6. Sun, Y.J.; Bigi, J.P.; Piro, N.A.; Tang, M.L.; Long, J.R.; Chang, C.J. Molecular cobalt pentapyridine catalysts for generating hydrogen from water. J. Am. Chem. Soc. 2011, 133, 9212-9215. [CrossRef] [PubMed]

7. Grasemann, M.; Laurenczy, G. Formic acid as a hydrogen source-recent developments and future trends. Energy Environ. Sci. 2010, 5, 8171-8181. [CrossRef]

8. Li, W.; Wang, X.; Xiong, D.; Liu, L. Efficient and durable electrochemical hydrogen evolution using cocoon-like $\mathrm{MoS}_{2}$ with preferentially exposed edges. Int. J. Hydrogen Energy 2016, 41, 9344-9354. [CrossRef]

9. You, B.; Jiang, N.; Sun, Y.J. Morphology-activity correlation in hydrogen evolution catalyzed by cobalt sulfides. Inorg. Chem. Front. 2016, 3, 279-285. [CrossRef] 
10. Iwasa, N.; Takezawa, N. New supported Pd and Pt alloy catalysts for steam reforming and dehydrogenation of methanol. Top. Catal. 2003, 22, 215-224. [CrossRef]

11. Kuo, C.H.; Tang, Y.; Chou, L.Y.; Sneed, B.T.; Brodsky, C.N.; Zhao, Z.P.; Tsung, C.K. Yolk-shell nanocrystal@ZIF-8 nanostructures for gas-phase heterogeneous catalysis with selectivity control. J. Am. Chem. Soc. 2012, 134, 14345-14348. [CrossRef] [PubMed]

12. Nielsen, M.; Alberico, E.; Baumann, W.; Drexler, H.J.; Junge, H.; Gladiali, S.; Beller, M. Low-temperature aqueous-phase methanol dehydrogenation to hydrogen and carbon dioxide. Nature 2013, 495, 85-89. [CrossRef] [PubMed]

13. Jiang, N.; You, B.; Sheng, M.L.; Sun, Y.J. Electrodeposited cobalt-phosphorous-derived films as competent bifunctional catalysts for overall water splitting. Angew. Chem. Int. Ed. 2015, 54, 6251-6254. [CrossRef] [PubMed]

14. Liu, X.; You, B.; Jiang, N.; Sun, Y.J. Facile surface modification of ubiquitous stainless steel led to competent electrocatalysts for overall water splitting. ACS Sustain. Chem. Eng. 2017, 5, 4778-4784. [CrossRef]

15. Song, F.Z.; Zhu, Q.L.; Tsumori, N.; Xu, Q. Diamine-alkalized reduced graphene oxide: Immobilization of sub-2 $\mathrm{nm}$ palladium nanoparticles and optimization of catalytic activity for dehydrogenation of formic acid. ACS Catal. 2015, 5, 5141-5144. [CrossRef]

16. Song, F.Z.; Zhu, Q.L.; Xu, Q. Monodispersed PtNi nanoparticles deposited on diamine-alkalized graphene for highly efficient dehydrogenation of hydrous hydrazine at room temperature. J. Mater. Chem. A 2015, 3, 23090-23094. [CrossRef]

17. Song, F.Z.; Zhu, Q.L.; Xu, Q. Monodispersed CuCo nanoparticles supported on diamine-functionalized graphene as a non-noble metal catalyst for hydrolytic dehydrogenation of ammonia borane. ChemNanoMat 2016, 2, 942-945. [CrossRef]

18. You, B.; Liu, X.; Jiang, N.; Sun, Y.J. A general strategy for decoupled hydrogen production from water splitting by integrating oxidative biomass valorization. J. Am. Chem. Soc. 2016, 138, 13639-13646. [CrossRef] [PubMed]

19. Zou, X.; Zhang, Y. Noble metal-free hydrogen evolution catalysts for water splitting. Chem. Soc. Rev. 2015, 44, 5148-5180. [CrossRef] [PubMed]

20. Chen, X.B.; Shen, S.H.; Guo, L.J.; Mao, S.S. Semiconductor-based photocatalytic hydrogen generation. Chem. Rev. 2010, 110, 6503-6570. [CrossRef] [PubMed]

21. Nasalevich, M.A.; van der Veen, M.; Kapteijn, F.; Gascon, J. Metal-organic frameworks as heterogeneous photocatalysts: Advantages and challenges. CrystEngComm 2014, 16, 4919-4926. [CrossRef]

22. Fujishima, A.; Honda, K. Electrochemical photolysis of water at a semiconductor electrode. Nature 1972, 238, 37-38. [CrossRef] [PubMed]

23. Khan, S.U.M.; Al-Shahry, M.; Ingler, W.B., Jr. Efficient photochemical water splitting by a chemically modified n-TiO 2 . Science 2002, 297, 2243-2245. [CrossRef] [PubMed]

24. Ye, J.H.; Zou, Z.G.; Matsushita, A. A novel series of water splitting photocatalysts $\mathrm{NiM}_{2} \mathrm{O}_{6}(\mathrm{M}=\mathrm{Nb}, \mathrm{Ta})$ active under visible light. Int. J. Hydrogen Energy 2003, 28, 651-655. [CrossRef]

25. Ni, M.; Leung, M.K.H.; Leung, D.Y.C.; Sumathy, K. A review and recent developments in photocatalytic water-splitting using $\mathrm{TiO}_{2}$ for hydrogen production. Renew. Sustain. Energy Rev. 2007, 11, 401-425. [CrossRef]

26. Kudo, A.; Miseki, Y. Heterogeneous photocatalyst materials for water splitting. Chem. Soc. Rev. 2009, 38, 253-278. [CrossRef] [PubMed]

27. Maeda, K.; Domen, K. Photocatalytic water splitting: Recent progress and future challenges. J. Phys. Chem. Lett. 2010, 1, 2655-2661. [CrossRef]

28. Zhang, Y.; Tang, Y.; Liu, X.; Dong, Z.; Hng, H.H.; Chen, Z.; Sum, T.C.; Chen, X. Three-dimensional CdS-titanate composite nanomaterials for enhanced visible-light-driven hydrogen evolution. Small 2013, 9 , 996-1002. [CrossRef] [PubMed]

29. Hoskins, B.F.; Robson, R. Infinite polymeric frameworks consisting of three dimensionally linked rod-like segments. J. Am. Chem. Soc. 1989, 111, 5962-5964. [CrossRef]

30. Li, H.; Eddaoudi, M.; Keeffe, M.O.; Yaghi, O.M. Design and synthesis of an exceptionally stable and highly porous metal-organic framework. Nature 1999, 402, 276-279.

31. Yaghi, O.M.; Keeffe, M.O.; Ockwing, N.W.; Chae, H.K.; Eddaoudi, M.; Kim, J. Reticular synthesis and the design of new materials. Nature 2003, 423, 705-714. [CrossRef] [PubMed] 
32. Zhang, Z.J.; Zhao, Y.G.; Gong, Q.H.; Li, Z.; Li, J. MOFs for $\mathrm{CO}_{2}$ capture and separation from flue gas mixtures: the effect of multifunctional sites on their adsorption capacity and selectivity. Chem. Commun. 2013, 49, 653-661. [CrossRef] [PubMed]

33. Henninger, S.K.; Habib, H.A.; Janiak, C. MOFs as adsorbents for low temperature heating and cooling applications. J. Am. Chem. Soc. 2009, 131, 2776-2777. [CrossRef] [PubMed]

34. Shimizu, G.K.H.; Taylor, J.M.; Kim, S. Proton conduction with metal-organic frameworks. Science 2013, 341 , 354-355. [CrossRef] [PubMed]

35. Xu, H.; Cui, Y.J.; Chen, B.L.; Qian, G.D. A luminescent nanoscale metal-organic framework for sensing of nitroaromatic explosives. Chem. Commun. 2011, 47, 3153-3155. [CrossRef] [PubMed]

36. Xamena, F.X.L.; Corma, A.; Garcia, H. MOFs as catalysts: Activity, reusability and shape-selectivity of a Pd-containing MOF. J. Catal. 2007, 250, 294-298.

37. Horcajada, P.; Serre, C.; Maurin, G.; Ramsahye, N.A.; Balas, F.; Vallet-Regi, M.; Sebban, M.; Taulelle, F.; Ferey, G. Flexible porous metal-organic frameworks for a controlled drug delivery. J. Am. Chem. Soc. 2008, 130, 6774-6780. [CrossRef] [PubMed]

38. Liu, B.; Shioyama, H.; Akita, T.; Xu, Q. Metal-organic framework as a template for porous carbon synthesis. J. Am. Chem. Soc. 2008, 130, 5390-5391. [CrossRef] [PubMed]

39. Yang, S.J.; Kim, T.; Im, J.H.; Kim, Y.S.; Lee, K.; Jung, H.; Park, C.R. MOF-derived hierarchically porous carbon with exceptional porosity and hydrogen storage capacity. Chem. Mater. 2012, 24, 464-470. [CrossRef]

40. Sun, J.K.; Xu, Q. Functional materials derived from open framework templates/precursors: Synthesis and applications. Energy Environ. Sci. 2014, 7, 2071-2100. [CrossRef]

41. Zeng, L.; Guo, X.Y.; He, C.; Duan, C.Y. Metal-organic frameworks: Versatile materials for heterogeneous photocatalysis. ACS Catal. 2016, 6, 7935-7947. [CrossRef]

42. Kataoka, Y.; Sato, K.; Miyazaki, Y.; Masuda, K.; Tanaka, H.; Naito, S.; Mori, W. Photocatalytic hydrogen production from water using porous material $\left[\mathrm{Ru}_{2}(\mathrm{p}-\mathrm{BDC})_{2}\right]_{n}$. Energy Environ. Sci. 2009, 2, 397-400. [CrossRef]

43. Kataoka, Y.; Miyazaki, Y.; Sato, K.; Saito, T.; Nakanishi, Y.; Kiatagwa, Y.; Kawakami, T.; Okumura, M.; Yamaguchi, K.; Mori, W. Modification of MOF catalysts by manipulation of counter-ions: Experimental and theoretical studies of photochemical hydrogen production from water over microporous diruthenium (II, III) coordination polymers. Supramol. Chem. 2011, 23, 287-299. [CrossRef]

44. Kataoka, Y.; Sato, K.; Miyazaki, Y.; Suzuki, Y.; Tanaka, H.; Kitagawa, Y.; Kawakami, T.; Okumura, M.; Mori, W. Photocatalytic hydrogen production from water using heterogeneous two-dimensional rhodium coordination polymer $\left[\mathrm{Rh}_{2}(\mathrm{p}-\mathrm{BDC})_{2}\right]_{n}$. Chem. Lett. 2010, 39, 358-359. [CrossRef]

45. Silva, C.G.; Luz, I.; Xamena, F.X.L.; Corma, A.; Garcia, H. Water stable Zr-benzenedicarboxylate metal-organic frameworks as photocatalysts for hydrogen generation. Chem. Eur. J. 2010, 16, 11133-11138. [CrossRef] [PubMed]

46. Horiuchi, Y.; Toyao, T.; Saito, M.; Mochizuki, K.; Iwata, M.; Higashimura, H.; Anpo, M.; Matsuoka, M. Visible-light-promoted photocatalytic hydrogen production by using an amino-functionalized Ti(IV) metal-organic framework. J. Phys. Chem. C 2012, 116, 20848-20853. [CrossRef]

47. Wen, M.; Mori, K.; Kamegawa, T.; Yamashita, H. Amine-functionalized MIL-101(Cr) with imbedded platinum nanoparticles as a durable photocatalyst for hydrogen production from water. Chem. Commun. 2014, 50, 11645-11648. [CrossRef] [PubMed]

48. Fateeva, A.; Chater, P.A.; Ireland, C.P.; Tahir, A.A.; Khimyak, Y.Z.; Wiper, P.V.; Darwent, J.R.; Rosseinsky, M.J. A water-stable porphyrin-based metal-organic framework active for visible-light photocatalysis. Angew. Chem. Int. Ed. 2012, 51, 7440-7444. [CrossRef] [PubMed]

49. Wang, C.; Krafft, K.E.; Lin, W. Pt nanoparticles@photoactive metal-organic frameworks: Efficient hydrogen evolution via synergistic photoexcitation and electron injection. J. Am. Chem. Soc. 2012, 134, 7211-7214. [CrossRef] [PubMed]

50. Lin, R.; Shen, L.; Ren, Z.; Wu, W.; Tan, Y.; Fu, H.; Zhang, J.; Wu, L. Enhanced photocatalytic hydrogen production activity via dual modification of MOF and reduced graphene oxide on CdS. Chem. Commun. 2014, 50, 8533-8535. [CrossRef] [PubMed]

51. He, J.; Wang, J.; Chen, Y.; Zhang, J.; Duan, D.; Wang, Y.; Yan, Z. A dye-sensitized Pt@UiO-66(Zr) metal-organic framework for visible-light photocatalytic hydrogen production. Chem. Commun. 2014, 50, 7063-7066. [CrossRef] [PubMed] 
52. Zhou, T.; Du, Y.; Borgna, A.; Hong, J.; Wang, Y.; Han, J.; Zhang, W.; Xu, R. Post-synthesis modification of a metal-organic framework to construct a bifunctional photocatalyst for hydrogen production. Energy Environ. Sci. 2013, 6, 3229-3234. [CrossRef]

53. Thoi, V.S.; Sun, Y.; Long, J.R.; Chang, C.J. Complexes of earth-abundant metals for catalytic electrochemical hydrogen generation under aqueous conditions. Chem. Soc. Rev. 2013, 42, 2388-2400. [CrossRef] [PubMed]

54. Hisatomi, T.; Kubota, J.; Domen, K. Recent advances in semiconductors for photocatalytic and photoelectrochemical water splitting. Chem. Soc. Rev. 2014, 43, 7520-7535. [CrossRef] [PubMed]

55. Ran, J.; Zhang, J.; Yu, J.; Jaroniec, M.; Qiao, S.Z. Earth-abundant cocatalysts for semiconductor-based photocatalytic water splitting. Chem. Soc. Rev. 2014, 43, 7787-7812. [CrossRef] [PubMed]

56. Shi, Y.M.; Zhang, B. Recent advances in transition metal phosphide nanomaterials: Synthesis and applications in hydrogen evolution reaction. Chem. Soc. Rev. 2016, 45, 1529-1541. [CrossRef] [PubMed]

57. Xu, Y.; Kraft, M.; Xu, R. Metal-free carbonaceous electrocatalysts and photocatalysts for water splitting. Chem. Soc. Rev. 2016, 45, 3039-3052. [CrossRef] [PubMed]

58. Roger, I.; Shipman, M.A.; Symes, M.D. Earth-abundant catalysts for electrochemical and photoelectrochemical water splitting. Nat. Rev. Chem. 2017, 1, 0003. [CrossRef]

59. Anantharaj, S.; Ede, S.R.; Sakthikumar, K.; Karthick, K.; Mishra, S.; Kundu, S. Recent trends and perspectives in electrochemical water splitting with an emphasis on sulfide, selenide, and phosphide catalysts of Fe, Co, and Ni: A review. ACS Catal. 2016, 6, 8069-8097. [CrossRef]

60. Nasalevich, M.A.; Becker, R.; Ramos-Fernandez, E.V.; Castellanos, S.; Veber, S.L.; Fedin, M.V.; Kapteijn, F.; Reek, J.N.H.; Vlugt, J.I.; Gascon, J. Co@NH2-MIL-125(Ti): Cobaloxime-derived metal-organic framework-based composite for lightdriven $\mathrm{H}_{2}$ production. Energy Environ. Sci. 2015, 8, 364-375. [CrossRef]

61. Zhang, T.; Lin, W.B. Metal-organic frameworks for artificial photosynthesis and photocatalysis. Chem. Soc. Rev. 2014, 43, 5982-5993. [CrossRef] [PubMed]

62. Zhang, C.; Ai, L.; Jiang, J. Solvothermal synthesis of MIL-53(Fe) hybrid magnetic composites for photoelectrochemical water oxidation and organic pollutant photodegradation under visible light. J. Mater. Chem. A 2015, 3, 3074-3081. [CrossRef]

63. Wang, S.B.; Wang, X.C. Multifunctional metal-organic frameworks for photocatalysis. Small 2015, 11, 3097-3112. [CrossRef] [PubMed]

64. Wang, C.; Xie, Z.G.; Krafft, K.E.; Lin, W.B. Doping metal organic frameworks for water oxidation, carbon dioxide reduction, and organic photocatalysis. J. Am. Chem. Soc. 2011, 133, 13445-13454. [CrossRef] [PubMed]

65. Wang, C.; Wang, J.L.; Lin, W.B. Elucidating molecular iridium water oxidation catalysts using metal-organic frameworks: A comprehensive structural, catalytic, spectroscopic, and kinetic study. J. Am. Chem. Soc. 2012, 134, 19895-19908. [CrossRef] [PubMed]

66. Chughtai, A.H.; Ahmad, N.; Younus, H.A.; Laypkov, A.; Verpoort, F. Metal-organic frameworks: Versatile heterogeneous catalysts for efficient catalytic organic transformations. Chem. Soc. Rev. 2015, 44, 6804-6849. [CrossRef] [PubMed]

67. You, B.; Jiang, N.; Sheng, M.; Gul, S.; Yano, J.; Sun, Y. High-performance overall water splitting electrocatalysts derived from cobalt-based metal-organic frameworks. Chem. Mater. 2015, 27, 7636-7642. [CrossRef]

68. You, B.; Jiang, N.; Sheng, M.; Drisdell, W.S.; Yano, J.; Sun, Y. Bimetal-organic framework self-adjusted synthesis of support-free nonprecious electrocatalysts for efficient oxygen reduction. ACS Catal. 2015, 5, 7068-7076. [CrossRef]

69. Liu, X.; Dong, J.; You, B.; Sun, Y. Competent overall water-splitting electrocatalysts derived from ZIF-67 grown on carbon cloth. RSC Adv. 2016, 6, 73336-73342. [CrossRef]

70. Wang, W.; Xu, X.; Zhou, W.; Shao, Z. Recent progress in metal-organic frameworks for applications in electrocatalytic and photocatalytic water splitting. Adv. Sci. 2017, 4, 1600371. [CrossRef] [PubMed]

71. Wang, J.L.; Wang, C.; Lin, W.B. Metal-organic frameworks for light harvesting and photocatalysis. ACS Catal. 2012, 2, 2630-2640. [CrossRef]

72. Xia, W.; Mahmood, A.; Zou, R.; Xu, Q. Metal-organic frameworks and their derived nanostructures for electrochemical energy storage and conversion. Energy Environ. Sci. 2015, 8, 1837-1866. [CrossRef]

73. Chaikittisilp, W.; Ariga, K.; Yamauchi, Y. A new family of carbon materials: Synthesis of MOF-derived nanoporous carbons and their promising applications. J. Mater. Chem. A 2013, 1, 14-19. [CrossRef] 
74. Khaletskaya, K.; Pougin, A.; Medishetty, R.; Rosler, C.; Wiktor, C.; Strunk, J.; Fischer, R.A. Fabrication of Gold/Titania photocatalyst for $\mathrm{CO}_{2}$ reduction based on pyrolytic conversion of the metal-organic rramework $\mathrm{NH}_{2}$-MIL-125(Ti) loaded with Gold nanoparticles. Chem. Mater. 2015, 27, 7248-7257. [CrossRef]

75. Xu, J.Y.; Zhai, X.P.; Gao, L.F.; Chen, P.; Zhao, M.; Yang, H.B.; Cao, D.F.; Wang, Q.; Zhang, H.L. In situ preparation of a MOF-derived magnetic carbonaceous catalyst for visible-light-driven hydrogen evolution. RSC Adv. 2016, 6, 2011-2018. [CrossRef]

76. Krafft, K.E.; Wang, C.; Lin, W.B. Metal-organic framework templated synthesis of $\mathrm{Fe}_{2} \mathrm{O}_{3} / \mathrm{TiO}_{2}$ nanocomposite for hydrogen production. Adv. Mater. 2012, 24, 2014-2018. [CrossRef] [PubMed]

77. Pham, M.H.; Dinh, C.T.; Vuong, G.T.; Ta, N.D.; Do, T.O. Visible light induced hydrogen generation using a hollow photocatalyst with two cocatalysts separated on two surface sides. Phys. Chem. Chem. Phys. 2014, 16, 5937-5941. [CrossRef] [PubMed]

78. Zhang, Y.F.; Giu, L.G.; Yuan, Y.P.; Zhu, Y.J.; Jiang, X.; Xiao, J.D. Magnetic $\mathrm{Fe}_{3} \mathrm{O}_{4} @ \mathrm{C} / \mathrm{Cu}$ and $\mathrm{Fe}_{3} \mathrm{O}_{4} @ \mathrm{CuO}$ core-shell composites constructed from MOF-based materials and their photocatalytic properties under visible light. Appl. Catal. B Environ. 2014, 144, 863-869. [CrossRef]

79. Bala, S.; Mondal, I.; Goswami, A.; Pal, U.; Mondal, R. Co-MOF as a sacrificial template: manifesting a new $\mathrm{Co}_{3} \mathrm{O}_{4} / \mathrm{TiO}_{2}$ system with a $\mathrm{p}-\mathrm{n}$ heterojunction for photocatalytic hydrogen evolution. J. Mater. Chem. A 2015, 3, 20288-20296. [CrossRef]

80. Jayaramulu, K.; Toyao, T.; Ranc, V.; Rosler, C.; Petr, M.; Zboril, R.; Horiuchi, Y.; Matsuoka, M.; Fischer, R.A. An in situ porous cuprous oxide/nitrogen-rich graphitic carbon nanocomposite derived from a metal-organic framework for visible light driven hydrogen evolution. J. Mater. Chem. A 2016, 4, 18037-18042. [CrossRef]

(C) 2017 by the authors. Licensee MDPI, Basel, Switzerland. This article is an open access article distributed under the terms and conditions of the Creative Commons Attribution (CC BY) license (http:/ / creativecommons.org/licenses/by/4.0/). 